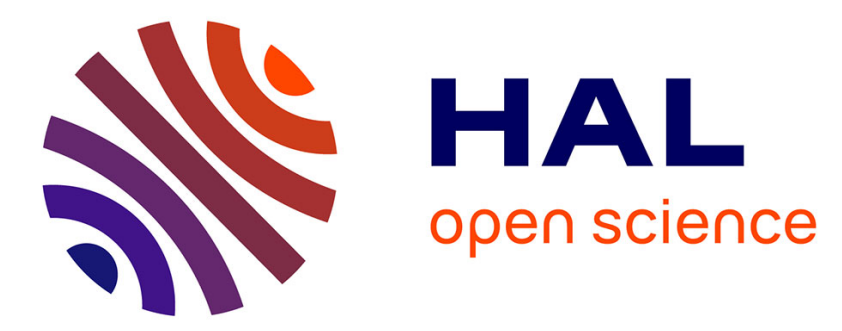

\title{
Detailled characterisation of SOI n-FinFETs at very low temperature
}

\author{
H. Achour, Bogdan Cretu, Jean-Marc Routoure, Régis Carin, Rachida \\ Talmat, A. Benfdila, E. Simoen, C. Claeys
}

\section{To cite this version:}

H. Achour, Bogdan Cretu, Jean-Marc Routoure, Régis Carin, Rachida Talmat, et al.. Detailled characterisation of SOI n-FinFETs at very low temperature. International Conference on Ultimate Integration on Silicon (ULIS), Mar 2013, Coventry, United Kingdom. 4 p. hal-00994224

\section{HAL Id: hal-00994224 \\ https://hal.science/hal-00994224}

Submitted on 22 Jul 2014

HAL is a multi-disciplinary open access archive for the deposit and dissemination of scientific research documents, whether they are published or not. The documents may come from teaching and research institutions in France or abroad, or from public or private research centers.
L'archive ouverte pluridisciplinaire HAL, est destinée au dépôt et à la diffusion de documents scientifiques de niveau recherche, publiés ou non, émanant des établissements d'enseignement et de recherche français ou étrangers, des laboratoires publics ou privés. 


\title{
Detailled characterisation of SOI n-FinFETs at very low temperature
}

\author{
H. Achour ${ }^{1,4}$, B. Cretu ${ }^{2}$, J.-M. Routoure ${ }^{1}$, R. Carin ${ }^{1}$, R. Talmat ${ }^{1,4}$, A. Benfdila ${ }^{4}$, E. Simoen ${ }^{5}$ and C. Claeys ${ }^{5,6}$ \\ ${ }^{1}$ University of Caen Basse-Normandie, UMR 6072 GREYC, F-14050, Caen, France \\ ${ }^{2}$ ENSICAEN, UMR 6072 GREYC, F-14050, Caen, France \\ ${ }^{3}$ CNRS, UMR 6072 GREYC, F-14032, Caen, France \\ ${ }^{4}$ GRMNT, Mouloud Mammeri University of Tizi-Ouzou, Algeria \\ ${ }^{5}$ Imec, Kapeldreef 75, B-3001 Leuven, Belgium \\ ${ }^{6}$ E.E. Dept. KU Leuven, Kasteelpark Arenberg 10, B-3001 Leuven, Belgium
}

Corresponding author: bogdan.cretu@ensicaen.fr

\begin{abstract}
DC and low frequency noise measurements on strained and unstrained n-channel FinFET transistors processed on silicon on insulator (SOI) substrates were performed at $10 \mathrm{~K}$ in order to evaluate the device performances and study the low frequency noise mechanisms. The main electrical parameters are investigated and compared to those found at room temperature. The low frequency noise analysis shows that at $10 \mathrm{~K}$, the carrier number fluctuations dominate the flicker noise in weak inversion, while the access resistance noise contributions prevails in strong inversion.
\end{abstract}

Keywords: FinFET, DC performances, low frequency noise, very low temperature operation

\section{INTRODUCTION}

The multi-gate FinFET has been considered as a promising structure for the future technology nodes, because the 3D geometry offers an improved control of the short-channel effects through a better electrostatic control of the gate over the conduction channel, allowing to achieve a higher $\mathrm{I}_{\mathrm{on}} / \mathrm{I}_{\text {off }}$ ratio, and providing an enhanced mobility due to the undoped channel [1-2]. However, the FinFETs still need to reach a higher $\mathrm{I}_{\text {on }}$ to meet the technology requirements. Strain engineering can further boost the device mobility without adding major process complexity [3-4].

Among all parameters that characterize these devices, the impact of the low frequency noise now plays a major role because its level increases continuously with the miniaturization. However, up to now, the noise behaviour in multi-gate n-channel FinFETs has never been investigated at $10 \mathrm{~K}$.

This work is focused on a thorough characterization on unstrained and strained SOI n-channel FinFETs at very low temperature operation in terms of short channel effects and low frequency noise performances.

\section{DEVICES AND EXPERIMENTAL}

\section{A. Devices}

The investigated devices are n-channel tri-gate FinFETs processed in a $32 \mathrm{~nm}$ technology with standard and strained SOI substrates. The gate oxide consists of a high-k dielectric (HfSiON) on top of a $1 \mathrm{~nm}$ interfacial $\mathrm{SiO}_{2}$ resulting in an equivalent oxide thickness (EOT) of $1.5 \mathrm{~nm}$. The metal gate consists of $10 \mathrm{~nm}$ TiN covered by $100 \mathrm{~nm}$ polysilicon. The devices have a fin width of $25 \mathrm{~nm}$, fin height of $65 \mathrm{~nm}, 5$ fins in parallel and a mask gate length $\left(\mathrm{L}_{\mathrm{G}}\right)$ varying from 130 to $1000 \mathrm{~nm}$. The tested devices are n-channel FinFETs on standard SOI substrates (SOI) and on biaxial globally strained substrates sSOI combined with uniaxial local strain by CESL (Contact Etch Stop Layers) and using SEG (Selective Epitaxial Growth) in the drain and source regions (sSOI + CESL +SEG).

\section{B. Experimental}

The DC and the low frequency noise measurements were performed directly at wafer-level using a Lakeshore TTP4 prober at $10 \mathrm{~K}$ and at room temperature. Static measurements were performed using an HP4156B semiconductor parameter analyser. In linear regime operation, the devices were biased with an applied drain voltage $V_{D S}=20 \mathrm{mV}$. In saturation regime, $I_{D}\left(V_{D S}\right)$ measurements were performed for different applied gate voltage $\mathrm{V}_{\mathrm{GS}}$ from $0.6 \mathrm{~V}$ up to $1 \mathrm{~V}$.

The noise measurement set-up allows to bias the devices by choosing the $\mathrm{V}_{\mathrm{GS}}$ and $\mathrm{V}_{\mathrm{DS}}$ voltages, and also to measure the total dynamic resistance between drain and source $\mathrm{r}_{\mathrm{T}}$ and the transconductance $\mathrm{g}_{\mathrm{m}}$ by applying a small signal at the source and gate nodes, respectively. Drain current fluctuations are amplified and the noise spectral density is calculated using a FFT spectral analyser. Noise is reported at the input of the device by dividing by the square of the measured voltage gain 
between the gate and the output and this for different applied gate voltages.

The linear regime operation measurements were performed for all available gate lengths. The saturation regime operation was investigated for all available gate lengths at room temperature, while at $10 \mathrm{~K}$ the measurements were focused only on three mask gate lengths of $130 \mathrm{~nm}, 250 \mathrm{~nm}$ and $700 \mathrm{~nm}$. The low frequency noise measurements were focused only on two mask gate lengths $(200 \mathrm{~nm}$ and $1000 \mathrm{~nm})$.

\section{RESULTS AND DISCUSSION}

\section{A. Static measurements}

Typical drain current $\mathrm{I}_{\mathrm{D}}\left(\mathrm{V}_{\mathrm{GS}}\right)$ and transconductance $\mathrm{g}_{\mathrm{m}}\left(\mathrm{V}_{\mathrm{GS}}\right)$ characteristics for a standard and strained $\mathrm{n}$-channel FinFET at $10 \mathrm{~K}$ for various gate lengths are shown in Fig. 1(a) and (b). Good behavior is obtained and one can note that the benefit of the use of strain seems to be preserved at this cryogenic temperature.

In order to eliminate the effects of the mobility gate voltage dependence at very low temperature operation, as proposed in [5], an adapted function defined as $\left(\mathrm{I}_{\mathrm{D}}\right)^{2 / 3} /\left(\mathrm{g}_{\mathrm{m}}\right)^{1 / 3}$ was constructed. As expected, linear dependence of this function (noted $\mathrm{Y}_{10 \mathrm{~K}}$ ) with the applied gate voltage is observed (Fig. 2), allowing us, by following the technique described in [5] to extract at $10 \mathrm{~K}$ operation the main electrical parameters of the transistors. At room temperature operation the electrical parameters are extracted following the technique using the $\mathrm{Y}$ function proposed in [6]

In Fig. 3 are plotted the extracted threshold voltage $\left(V_{t}\right)$ for all the investigated mask gate lengths. Short channel effects are only slightly ameliorated with the temperature reduction: $\quad \mathrm{V}_{\mathrm{t}}($ long-channel $)-\mathrm{V}_{\mathrm{t}}($ short-channel $)$ for standard SOI devices is about $52 \mathrm{mV} @ 300 \mathrm{~K}$ compared to $49 \mathrm{mV} @ 10 \mathrm{~K}$, while for strained ones it is about 67 mV@300K compared to53 mV@10 K. Moreover, by reducing the temperature, the shift of the threshold voltage $\mathrm{V}_{t}(300 \mathrm{~K})-\mathrm{V}_{\mathrm{t}}(10 \mathrm{~K})$ for the SOI devices is about $110 \mathrm{mV}$ for $\mathrm{L}_{\mathrm{G}}=1000 \mathrm{~nm}$ and $93 \mathrm{mV}$ for $\mathrm{L}_{\mathrm{G}}=160 \mathrm{~nm}$, while in sSOI device it is about $41 \mathrm{mV}$ for $\mathrm{L}_{\mathrm{G}}=1000 \mathrm{~nm}$ and $35 \mathrm{mV}$ for $\mathrm{L}_{\mathrm{G}}=160 \mathrm{~nm}$, resulting in a lower threshold voltage for the strained channels at $10 \mathrm{~K}$. These threshold voltage shift values are lower than expected by the reduction of the temperature from $300 \mathrm{~K}$ down to $10 \mathrm{~K}$ (i.e. about $165 \mathrm{mV}$ [7]). This could be related to the temperature behaviour of the Fermi level and of the surface potential at very low temperatures which are caused primarily by the temperature dependence of the intrinsic carrier concentration.

As provided by the extraction techniques, the low field mobility can be estimated at room temperature, while at $10 \mathrm{~K}$ it is the maximum of the effective mobility (see Table 1). As expected, a boost in the extracted low field mobility is observed for the strained devices at room temperature. At $10 \mathrm{~K}$, due to reduced phonon scattering, an enhanced mobility is expected. By reducing the temperature from $300 \mathrm{~K}$ to $10 \mathrm{~K}$, one observes that the increase of the mobility is more pronounced for standard devices compared to the strained ones. This trend can be justified by a more pronounced impact of the surface roughness mechanism in strained devices at this cryogenic temperature.

One of the problems related with the use of narrow nFinFETs is the increase of the parasitic series resistance. The access resistance and the difference between mask and effective gate length $\left(\Delta \mathrm{L}=\mathrm{L}_{\mathrm{m}}-\mathrm{L}_{\text {eff }}\right)$ are extracted following the total resistance technique described in [8]. Compared with standard devices, the introduction of SEG allows to obtain a significant reduction of the access resistance of about $60 \%$ at room temperature and of about $50 \%$ at $10 \mathrm{~K}$. For a given temperature, the obtained values of $\Delta \mathrm{L}$ are quite similar for standard and strained devices. This suggests that the charge sharing effect is not significantly affected by the use of the strain. However, as expected, amelioration is observed at very low temperature operation.

\begin{tabular}{|c|c|c|c|c|}
\hline \multirow{2}{*}{} & \multicolumn{2}{|c|}{ SOI } & \multicolumn{2}{c|}{ sSOI+CESL+SEG } \\
\cline { 2 - 5 } & $\mathbf{1 0 ~ K}$ & $\mathbf{3 0 0} \mathbf{~}$ & $\mathbf{1 0 ~ K}$ & $\mathbf{3 0 0} \mathbf{~}$ \\
\hline $\boldsymbol{\mu ( \mathbf { c m } ^ { 2 } / \mathbf { V s } )}$ & 490 & 220 & 653 & 530 \\
\hline $\mathbf{R}_{\text {access }}(\boldsymbol{\Omega})$ & 178 & 210 & 84 & 123 \\
\hline$\Delta \mathbf{L} \mathbf{( n m})$ & 18 & 54 & 22 & 49 \\
\hline
\end{tabular}

TABLE 1 . Summary of the extracted values for the mobility, access resistance and $\Delta \mathrm{L}$ at room and $10 \mathrm{~K}$ operation.
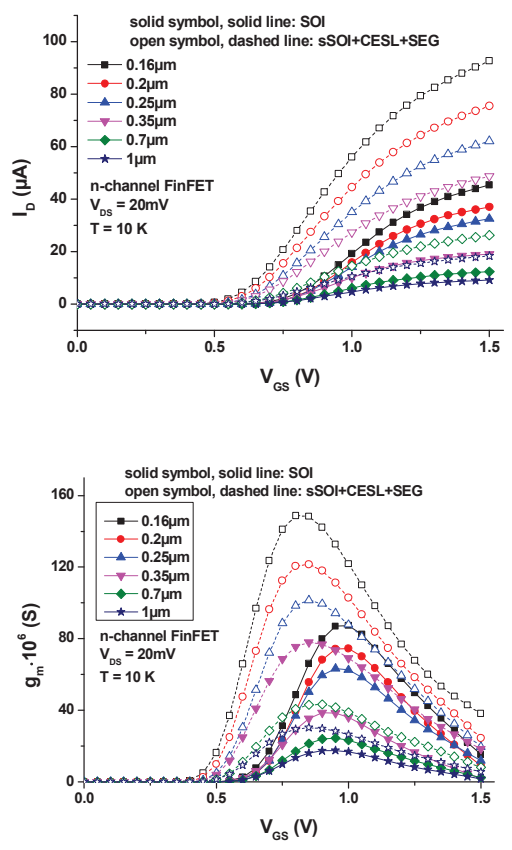

Figure 1. Typical $\mathrm{I}_{\mathrm{D}}\left(\mathrm{V}_{\mathrm{GS}}\right)$ and $\mathrm{g}_{\mathrm{m}}\left(\mathrm{V}_{\mathrm{GS}}\right)$ characteristics for various gate lengths at $10 \mathrm{~K}$. 


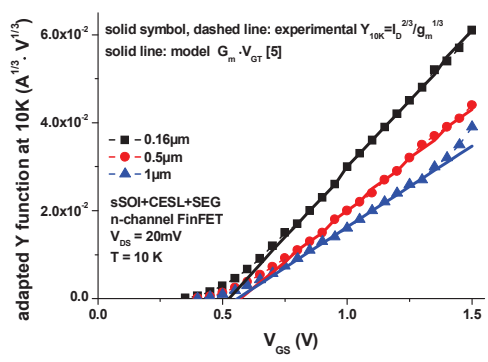

Figure 2. Typical $\mathrm{Y}_{10 \mathrm{~K}}\left(\mathrm{~V}_{\mathrm{GS}}\right)$ characteristics for various gate length at $10 \mathrm{~K}$

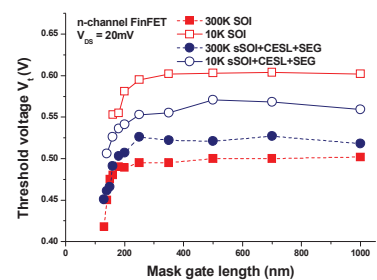

Figure 3. Extracted threshold voltage at $10 \mathrm{~K}$ and room temperature

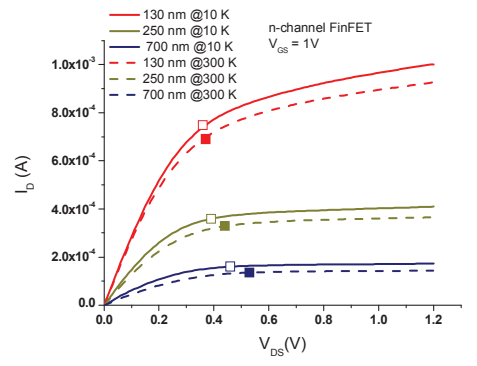

Figure 4. Typical $\mathrm{I}_{D}\left(\mathrm{~V}_{\mathrm{DS}}\right)$ characteristics for various gate lengths at $10 \mathrm{~K}$ and $300 \mathrm{~K}$

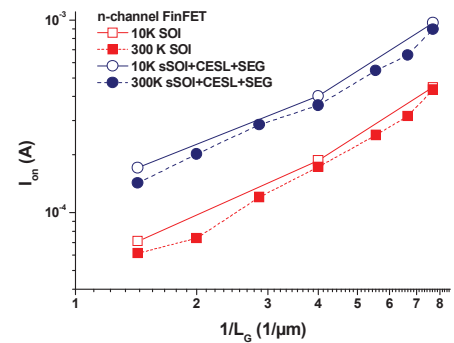

Figure 5. $\mathrm{I}_{\mathrm{on}}$ versus the mask gate length at $10 \mathrm{~K}$ and $300 \mathrm{~K}$

Fig. 4 shows typical drain current $\mathrm{I}_{\mathrm{D}}\left(\mathrm{V}_{\mathrm{DS}}\right)$ characteristics for a fixed applied gate voltages of $1 \mathrm{~V}$ and for different channel mask gate lengths at the two investigated temperatures. Reducing temperature leads to a slight increase of the saturation drain current $\mathrm{I}_{\text {Dsat }}$ and a small reduction of the saturation voltage $V_{\text {Dsat }}$. The $I_{\text {on }}$ currents, defined as $\mathrm{I}_{\mathrm{on}}=\mathrm{I}_{\mathrm{DS}} @ \mathrm{~V}_{\mathrm{DS}}=\mathrm{V}_{\mathrm{GS}}=1 \mathrm{~V}$ are plotted in Fig. 5. It is worth noting that $\mathrm{I}_{\text {on }}$ is higher in strained devices compared to standard ones. A temperature reduction leads to an enhancement of the $\mathrm{I}_{\mathrm{on}}$ current. This increase is more pronounced for short- channel transistors (about $17-20 \%$ ) compared to long channel transistors (about $8-10 \%$ ) for both structures.

The drift velocity can be defined as $\mathrm{v}_{\mathrm{d}}=\mathrm{g}_{\mathrm{m}} /\left(\mathrm{W} \mathrm{C}_{\mathrm{ox}}\right)$. This drift velocity increases with the drain voltage and reaches a maximum at high electric field. For an applied drain voltage higher than the saturation voltage, this maximum is weakly dependent on the applied gate bias. The extracted values corrected by access resistance influence are shown in Fig. 6. As expected from theory, $\mathrm{v}_{\mathrm{d}}$ is found to vary as the inverse of the channel length even for the short devices due to prevailing mobility limited transport. The use of strain leads to enhanced values of the saturation velocity. Therefore, reducing temperature increases the drift velocity for both devices due to the reduced phonon scattering contribution. It may be noted that at $10 \mathrm{~K}$, the estimated drift velocity for the short-channel strained devices (about $10.9 \cdot 10^{6} \mathrm{~cm} \cdot \mathrm{s}^{-1}$ for $\mathrm{L}_{\mathrm{G}}=130 \mathrm{~nm}$ ) is very close to the value of the nonstationary regime at this temperature (i.e. $13.2 \cdot 10^{6} \mathrm{~cm} \cdot \mathrm{s}^{-1}$ [9]).

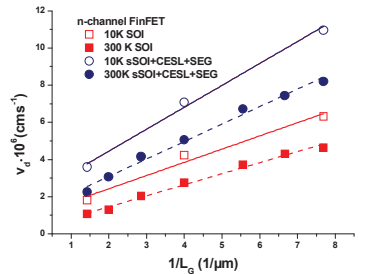

Figure 6. Intrinsic drift velocity versus gate length at $10 \mathrm{~K}$ and $300 \mathrm{~K}$.

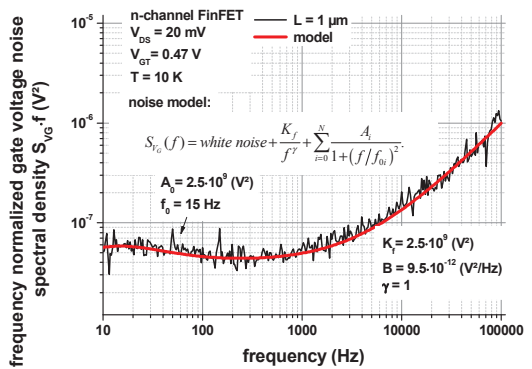

Figure 7. Comparison between noise measurement and model using inset equation. In this example, $1 / \mathrm{f}$ noise, white noise and one Lorentzian contribution were used to obtain the best adjustment between the model and the measurement.

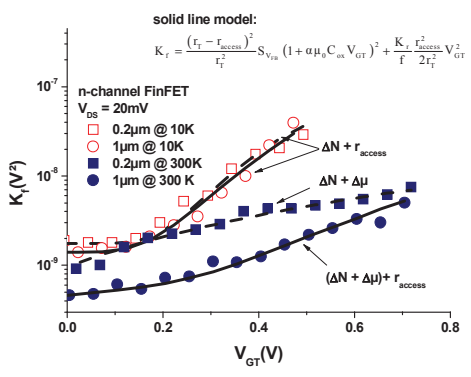

Figure 8. The extracted $\mathrm{K}_{\mathrm{f}}\left(\mathrm{V}_{\mathrm{GT}}\right)$ for the standard device for two channel lengths at $10 \mathrm{~K}$ and $300 \mathrm{~K}$. 


\section{B. Low frequency noise}

In Fig. 7 is represented an example of the frequency normalized gate voltage noise spectral density at $10 \mathrm{~K}$. The total noise can be perfectly modelled by considering three uncorrelated noise sources: white noise, $1 / \mathrm{f}$ and Lorentzian noise (see equation in the inset of Fig. 7), and each contribution can be identified. The extracted 1/f noise level $\left(\mathrm{K}_{\mathrm{f}}\right)$ variations with the applied gate voltage overdrive $\left(\mathrm{V}_{\mathrm{GT}}=\mathrm{V}_{\mathrm{GS}}-\mathrm{V}_{\mathrm{t}}\right)$ are illustrated in Fig. 8 for two mask gate lengths of the standard devices at the two investigated temperatures.

At room temperature, the $1 / \mathrm{f}$ noise behaviour was already discussed in [10] and attributed to carrier number fluctuations due to carrier trapping in the oxide layer. At $10 \mathrm{~K}$ operation, the extracted $1 / \mathrm{f}$ noise level is found to be independent on the variations of the applied gate overdrive in weak inversion. This suggests that carrier number fluctuations dominate the $1 / \mathrm{f}$ noise [11] even at this cryogenic temperature. The increase of the noise in strong inversion can be modelled by taking into account only parasitic access resistance contributions for both investigated channel lengths. The solid line in Fig. 8 represents the 1/f noise model which takes into account carrier number fluctuation and parasitic access resistance contributions (see equation in the inset of Figure 8).

\begin{tabular}{|c|c|c|c|c|c|c|}
\hline & $\begin{array}{c}\mathrm{T} \\
(\mathrm{K})\end{array}$ & $\begin{array}{c}\mathrm{L} \\
(\mu \mathrm{m})\end{array}$ & $\begin{array}{c}\mathrm{S}_{\mathrm{VFB}} \cdot 10^{-9} \\
\left(\mathrm{~V}^{2} / \mathrm{Hz}\right)\end{array}$ & $\mathrm{K}_{\mathrm{r}} \cdot 10^{-5}$ & $\begin{array}{l}\alpha \cdot 10^{4} \\
(\mathrm{Vs} / \mathrm{C})\end{array}$ & $\begin{array}{c}\mathrm{N}_{\mathrm{it}} \cdot 10^{17} \\
\left(\mathrm{~cm}^{-3} \mathrm{eV}^{-1}\right)\end{array}$ \\
\hline \multirow{4}{*}{ SOI } & \multirow{2}{*}{$10 \mathrm{~K}$} & 0.2 & 1.75 & 1.5 & & 610 \\
\hline & & 1 & 1.25 & 18 & & 2630 \\
\hline & \multirow{2}{*}{$300 \mathrm{~K}$} & 0.2 & 0.96 & 0 & 0.5 & 11 \\
\hline & & 1 & 0.45 & 6.5 & 0.14 & 29 \\
\hline
\end{tabular}

TABLE 2. Summary of the extracted noise parameters for standard devices at $10 \mathrm{~K}$ and $300 \mathrm{~K}$.

In Table 2 are summarized the main extracted noise parameters. It was already reported that reducing the temperature can lead to enhanced noise levels in n-MOSFETs [12]. An increase of the flat-band noise level is observed in our devices with temperature reduction from $300 \mathrm{~K}$ down to $10 \mathrm{~K}$. This increase is more important for the long - channel devices (a factor of about 2.7) compared to short - channel ones (a factor of about 1.8).

The impact of the carrier number fluctuations correlated to mobility fluctuations are observed only at room temperature. The estimated values of the scattering coefficient suggest that the $\Delta \mathrm{N}+\Delta \mu$ noise mechanism is more important in short-channel devices. However, they are lower than typical values reported for planar bulk nchannel transistors (i.e. $10^{4} \mathrm{Vs} / \mathrm{C}$ ).

The relatively small values of the slow insulator trap density are a good indication of the quality of the oxidation process despite the using of high-k dielectrics in such advanced devices. At $10 \mathrm{~K}$, the increase of the trap densities is observed, this trend was already reported [12] and can be justified by models which take into account the structure of the high-k dielectric stack considering two tunnelling barriers through the dielectric, corresponding to the interfacial layer and to the high-k layer, respectively.

\section{CONCLUSION}

Good I-V characteristics were evidenced even at $10 \mathrm{~K}$. Better behaviour of the strained devices has been observed for many electrical parameters at $10 \mathrm{~K}$ operation: lower threshold voltage, smaller access resistance, higher carrier mobility, higher $\mathrm{I}_{\text {on }}$ current and higher saturation drift velocity. For short-channel strained devices, the values of the saturation velocity are very close to those of the non-stationary regime. The use of strain seems to have no significant impact on the charge sharing effect. However, the benefit of the strain engineering is maintained at this cryogenic temperature.

The carrier number fluctuations dominate the $1 / \mathrm{f}$ noise also at very low temperature. The correlated mobility fluctuations contributions were not observed at $10 \mathrm{~K}$. In strong inversion, more impact of the access resistance noise contribution to the total $1 / \mathrm{f}$ noise is found at $10 \mathrm{~K}$. The quality of the oxidation process was proved by the small values of the oxide trap density.

\section{REFERENCES}

[1] J. Colinge, "Multi-gate SOI MOSFETs", Microelectronic Eng.; 84(9-10):2071-2076, 2007.

[2] T. Skotnicki, "Materials and device structures for sub-32 nm CMOS nodes", Microelectronic Eng.; 84 (9-10):1845-1852, 2007.

[3] E. Parton, P. Verheyen, "Strained silicon - the key to sub-45 nm CMOS. III-Vs review", Advanced Semiconductor Magazine;19(3):28 - 32, 2006.

[4] C. Claeys, E. Simoen, S. Put, G. Giusi, F. Crupi, "Impact strain engineering on gate stack quality and reliability", Solid State Electron., 52(8):1115-1126, 2008

[5] G. Ghibaudo, F. Balestra, "A method for MOSFET parameter extraction at very low temperature", Solid State Electron., 32(3):221-223, 1989.

[6] G. Ghibaudo, "A new method for the extraction of MOSFET parameters", Electron. Lett., 24, p. 543, 1988.

[7] R. Talmat, S. Put, N. Collaert, A. Mercha, C. Claeys, W. Guo, B. Cretu, A. Benfdila, J.-M. Routoure, R. Carin, E. Simoen, "High-temperature characterization of advanced strained nMuGFETs", In Proceedings of EUROSOI'2010 Conference 2527 January Grenoble France, 75-76, 2010

[8] G. Ghibaudo, "Critical MOSFETs operation for low voltage/low power IC's: Ideal characteristics parameter extraction, electrical noise and RTS fluctuations", Microelectronic Eng., 39:31-57, 1997.

[9] C. Jacoboni, C. Canali, G. Ottaviani, and A. A. Quaranta, "A review of some charge transport properties of silicon", Solid State Electron., 20(2), p. 77-89, 1977.

[10] R. Talmat, H. Achour, B. Cretu, J.-M. Routoure, A. Benfdila, R. Carin, N. Collaert, A. Mercha, E. Simoen, C. Claeys, "Low frequency noise characterization in n-channel FinFETs", Solid State Electron.,70:20-26, 2012.

[11] G. Ghibaudo, O. Roux, C. Nguyen-Duc, F. Balestra, J. Brini, "Improved analysis of low frequency noise in field-effect MOS transistors", Phys Stat Solidi (a), 124: 571-577, 1991.

[12] S. Christensson, I. Lundstrom, "Low-frequency noise in MOS transistors- II Experiments", Solid State Electron., 11, 813-820, 1968. 